\title{
Streptomyces costaricanus sp. nov., Isolated from Nematode-Suppressive Soil
}

\author{
JOSEPH ESNARD, ${ }^{1}$ THOMAS L. POTTER, ${ }^{2}$ AND BERT M. ZUCKERMAN ${ }^{1 *}$ \\ Department of Plant Pathology ${ }^{1}$ and Mass Spectrometry Facility, ${ }^{2}$ College of Food and Natural Resources, \\ University of Massachusetts, Amherst, Massachusetts 01003
}

\begin{abstract}
A new bacterial strain, strain CR-43 ${ }^{T}(T=$ type strain), which was isolated from tropical soil and was previously shown to have antinematodal and antibiotic properties, is described. The name Streptomyces costaricanus is proposed for this organism. The generic placement of strain CR-43 ${ }^{\mathrm{T}}$ was based on its typical morphology, its production of LL-diaminopimelic acid, and its fatty acid composition. To clarify the taxonomic position of strain CR-43 ${ }^{\mathrm{T}}$, it was compared with the type strains of similar Streptomyces species. The results of a number of biochemical tests and a profile analysis of the hydrolyzable fatty acids indicated that CR-43 differs from previously described species. Strain CR-43 (= ATCC 55274 = NRRL B-16897) is the type strain of $S$. costaricanus sp. nov.
\end{abstract}

Nematode-suppressive soils have been found in several locations throughout the world. In our laboratory, microorganisms with antinematodal or antifungal properties have been isolated from suppressive soils obtained from Mexico $(12,23)$ and Costa Rica (4). The biological basis of this suppressiveness was established by showing that heat sterilization abolishes the suppressive effect. One of the organisms isolated from suppressive soil obtained from Costa Rica exhibited both antinematodal and antifungal activities in laboratory, greenhouse, and field trials (4). A culture of this organism (designated strain CR $-43^{\mathrm{T}}[\mathrm{T}=$ type strain]) was submitted for identification to the American Type Culture Collection (ATCC), Rockville, $\mathrm{Md}$., which concluded that the isolate was a member of the genus Streptomyces and could not be placed in a previously described species (1). Later, a University of Massachusetts research team reported (4) that this isolate specifically inhibited reproduction of the free-living nematode Caenorhabditis elegans in vitro under axenic conditions. Such an effect is referred to as antinematodal activity, in contrast to the nematicidal activity exhibited by organisms such as Streptomyces avermitilis.

On the basis of the results of successful field trials in which the control of several species of plant parasites was examined, an application for a patent for CR- $43^{\mathrm{T}}$ as a biocontrol agent for nematodes was filed by Research Corporation Technologies, Tucson, Ariz., under exclusive license from the University of Massachusetts at Amherst. Cryopreserved subcultures of CR$43^{\mathrm{T}}$ have been deposited in the ATCC (as ATCC 55274 ) and in the U.S. Department of Agriculture Agricultural Research Service Culture Collection (as NRRL B-16897 $7^{\mathrm{T}}$ ).

In this paper we describe CR-43 ${ }^{\mathrm{T}}$ as a member of a new species, for which we propose the name Streptomyces costaricanus. This organism was compared with plant-pathogenic, anthelmintic, and other similar Streptomyces species.

\section{MATERIALS AND METHODS}

Microorganisms. Characteristics of nine previously described Streptomyces species were compared with characteristics of strain $C R-43^{\mathrm{T}}$, which was isolated from nematode-suppressive soil obtained in Costa Rica and stored at $-80^{\circ} \mathrm{C}$ in cryopreservation buffer (2). S. avermitilis ATCC $31267^{1}$ was obtained from the ATCC, while Streptomyces scabies ATCC $49173^{\mathrm{T}}$ and Streptomyces acidiscabies ATCC $49003^{\mathrm{T}}$, two plant-pathogenic organisms, were supplied by R. Loria, Cornell University, Ithaca, N.Y. Comparison with plant-parasitic streptomycetes

\footnotetext{
* Corresponding author.
}

was required by the Animal and Plant Health Inspection Service since CR-43 ${ }^{\mathrm{T}}$ was being introduced as a biological control agent for plant nematodes. $S$. avermitilis is a known anthelmintic species and therefore was appropriate for comparative studies. Members of six other species and subspecies (Streptomyces hygroscopicus NRRL B-1865 ${ }^{\mathrm{T}}$, Streptomyces murinus NRRL B-2286 ${ }^{\mathrm{T}}$, Streptomyces griseoluteus NRRL B-1315 , Streptomyces hygroscopicus subsp. decoyicus NRRL ISP-5087' Streptomyces rubiginosus NRRL B-3983 ${ }^{\mathrm{T}}$, and Streptomyces griseofuscus NRRL B-5429 ) have characteristics similar to CR-43 ${ }^{\mathrm{T}}$ characteristics and were obtained from David Labeda, U.S. Department of Agriculture, Peoria, Ill. All bacterial strains were stored at $-80^{\circ} \mathrm{C}$ as described above. Initially, all strains were grown on International Streptomyces Project (ISP) medium $2(17)$ at $28^{\circ} \mathrm{C}$. Data were supplemented or confirmed by using data for species characteristics published previously.

Morphological and cultural characterization. Light microscopy was used to study the aerial mycelium of strain CR $-43^{\mathrm{T}}$; the characteristics of this organism were then compared with the characteristics of the other type strains examined. Standards described by Shirling and Gottlieb (17) were used to describe spore chain morphology. Cultural characteristics of strain CR $-43^{\top}$ and S. hygroscopicus subsp. decoyicus were determined by using media recommended by the ISP (14, 17). The presence of soluble pigments was investigated on yeast extract-malt extract agar (ISP medium 2; $4 \mathrm{~g}$ of yeast extract [Difco] per liter, $10 \mathrm{~g}$ of malt extract [Difco] per liter, $4 \mathrm{~g}$ of glucose per liter; $\mathrm{pH} 7.3$ before $20 \mathrm{~g}$ of agar per liter was added), oatmeal agar (ISP medium 3), inorganic salts-starch agar (ISP medium 4), glycerol-asparagine agar (ISP medium 5), and ATCC medium 172. Melanoid pigment production was studied on peptone-yeast extract-iron agar (ISP medium 6) and tyrosine agar (ISP medium 7).

Carbon source utilization. Each carbon source was added at a final concentration of $1 \%(\mathrm{wt} / \mathrm{vol})$ and was prepared as a $10 \%$ solution in glass-distilled deionized water that was sterilized by passing it through a $0.22-\mu \mathrm{m}$-pore-size Acrodisc filter. The basal salt medium which we used has been described previously by Pridham and Gottlieb (14). The absence or presence of growth on each medium was recorded. The carbon source utilization data described below are data from this study. The data for different species shown in Table 1 were compared with previously published data $(3,9-11,18-21)$. The following 10 carbon sources were tested: L-arabinose, D-fructose, D-glucose, D-mannitol, raffinose, L-rhamnose, sucrose, D-xylose, salicin, and galactose. Acid production by strain CR-43 ${ }^{\mathrm{T}}$ was tested after growth in nocardia purple broth supplemented with cellobiose, D-glucose, glycerol, maltose, galactose, D-mannitol, D-xylose, L-arabinose, D-fructose, lactose, sucrose, ribitol, galactitol, erythritol, or i-inositol.

Antibiotics and other inhibitory compounds. Growth of the streptomycetes in the presence of streptomycin $(20 \mu \mathrm{g} / \mathrm{ml})$, penicillin $(10 \mathrm{IU} / \mathrm{ml})$, phenol $(0.1 \%)$, thallium acetate $(10 \mu \mathrm{g} / \mathrm{ml})$, and crystal violet $(0.5 \mu \mathrm{g} / \mathrm{ml})$ was tested in ISP medium 2.

$\mathrm{NaCl}$ tolerance. Sodium chloride tolerance was tested on yeast extract-malt extract agar (ISP medium 2) supplemented with 5,6 , or $7 \%$ (wt/vol) $\mathrm{NaCl}$.

pH sensitivity. The minimum $\mathrm{pH}$ that allowed growth was determined on modified ISP medium 2. The $\mathrm{pH}$ was adjusted with $1 \mathrm{M} \mathrm{HCl}$ or $0.25 \mathrm{M} \mathrm{KOH}$.

Cellular fatty acid profile analysis. $S$. costaricanus CR-43 ${ }^{\mathrm{T}}, S$. hygroscopicus, $S$. murinus, and $S$. griseoluteus were quadrant streaked onto ISP medium 2 agar and grown aerobically in the dark for $96 \mathrm{~h}$ at $28 \pm 0.1^{\circ} \mathrm{C}$. In another experiment, $S$. costaricanus CR-43 ${ }^{\mathrm{T}}, S$. hygroscopicus subsp. decoyicus, $S$. rubiginosus, and $S$. griseofuscus were grown at 27 to $28^{\circ} \mathrm{C}$ in ISP medium 2 broth with vigorous shaking for $72 \mathrm{~h}$. A fatty acid analysis was performed (in duplicate) as described by Esnard et al. (5). A Hewlett-Packard model HP5890 series II Plus gas chromatography-mass spectrometry system coupled to a model HP5972 mass selective detector was used. The gas chromatograph was equipped with a type HP-5 
TABLE 1. Characteristics of S. costaricanus, S. avermitilis, S. scabies, S. acidiscabies, S. murinus, S. hygroscopicus, S. hygroscopicus subsp. decoyicus, S. griseoluteus, S. rubiginosus, and $S$. griseofuscus

\begin{tabular}{|c|c|c|c|c|c|c|c|c|c|c|}
\hline Characteristic & $\begin{array}{c}S . \\
\text { costaricanus }^{a}\end{array}$ & $\begin{array}{c}S . \\
\text { avermitilis }^{b}\end{array}$ & $\begin{array}{c}S . \\
\text { scabies }^{c}\end{array}$ & $\begin{array}{c}S \\
\text { acidiscabies }^{c}\end{array}$ & $\begin{array}{c}S . \\
\text { hygroscopicus }^{d}\end{array}$ & $\begin{array}{l}\text { S. hygroscopicus } \\
\text { subsp. decoyicus }\end{array}$ & $\begin{array}{l}\text { S. } \\
\text { murinus }\end{array}$ & $\begin{array}{l}\text { S. } \\
\text { griseoluteus }\end{array}$ & $\begin{array}{l}\text { S. } \\
\text { nubiginosus }\end{array}$ & $\begin{array}{l}\text { S. } \\
\text { griseofuscus }\end{array}$ \\
\hline \multicolumn{11}{|l|}{$\begin{array}{l}\text { Spore mass color/substrate } \\
\text { mycelium color onf: }\end{array}$} \\
\hline ISP medium 2 & $\mathrm{~GB} / \mathrm{Y}$ & $\mathrm{BW} / \mathrm{dB}$ & $\mathrm{G} / \mathrm{G}$ & $\mathrm{W} / \mathrm{B}$ & G-B & $\mathrm{G} / \mathrm{CY}$ & $\mathrm{R}^{\prime} / \mathrm{Mo}$ & $\mathrm{G} / \pm$ & G & $\mathrm{R}, \mathrm{G}$ \\
\hline ISP medium 3 & $\mathrm{~GB} / \mathrm{B}$ & $\mathrm{BG} / \mathrm{dB}$ & $\mathrm{G} / \mathrm{G}$ & $\mathrm{W} / \mathrm{B}$ & G-B & $\mathrm{W}-\mathrm{CG} / \mathrm{B}$ & $\begin{array}{l}\text { R.G/ } \\
\text { GY }\end{array}$ & $\mathrm{G} / \pm$ & $\mathrm{G}$ & $\mathrm{R}, \mathrm{G}$ \\
\hline ISP medium 4 & $\mathrm{~GB} / \mathrm{Y}$ & $\mathrm{BG} / \mathrm{GY}$ & $\mathrm{G} / \mathrm{G}$ & $\mathrm{W} / \mathrm{B}$ & G-B & $\mathrm{GB} / \mathrm{BG}^{\prime}$ & G/Mo & $\mathrm{G} / \pm$ & G & $\mathrm{R}, \mathrm{G}$ \\
\hline Spore chain morphology $y^{g}$ & $\mathrm{sp}$ & $\mathrm{sp}$ & $\mathrm{sp}$ & $\mathrm{f}$ & $\mathrm{sp}$ & $\mathrm{sp}^{a}$ & $\mathrm{sp}$ & $\mathrm{rf}$ & $\mathrm{sp}$ & $\mathrm{sp}$ \\
\hline No. of spores per chain & $10-50$ & $>15$ & $\geq 20$ & $\geq 20$ & $>10^{a}$ & $>10^{a}$ & $10-50$ & $<10^{h}$ & $10-50$ & $10-50$ \\
\hline \multicolumn{11}{|l|}{$\begin{array}{l}\text { Production of melanoid } \\
\text { pigment on: }\end{array}$} \\
\hline ISP medium 6 & - & + & + & - & - & - & - & - & - & - \\
\hline ISP medium 7 & - & + & + & - & - & - & - & - & - & - \\
\hline \multicolumn{11}{|l|}{ Soluble pigment inf: } \\
\hline ISP medium 4 & - & YB & - & $\mathrm{Y} / \mathrm{R}^{j}$ & - & - & $\mathrm{Y}$ & R-BG & - & - \\
\hline ISP medium 5 & Y & YB & - & $\mathrm{Y} / \mathrm{R}$ & - & - & $\mathrm{Y}$ & ND & - & - \\
\hline $\begin{array}{l}\mathrm{pH} \text { effect on soluble pigment } \\
\text { production }\end{array}$ & - & ND & - & + & $-a$ & - & - & + & - & - \\
\hline \multicolumn{11}{|l|}{$\begin{array}{l}\text { Utilization of the following } \\
\text { carbon sources }{ }^{k} \text { : }\end{array}$} \\
\hline L-Arabinose & - & + & + & + & + & $\operatorname{tr}^{a}$ & $\operatorname{tr}$ & + & $-a$ & + \\
\hline D-Fructose & + & + & + & + & + & $+^{a}$ & + & + & + & + \\
\hline D-Glucose & + & + & + & + & + & $++^{a}$ & + & + & + & + \\
\hline D-Mannitol & + & + & + & + & + & $+^{a}$ & + & + & + & + \\
\hline Raffinose & - & + & + & - & - & $-a$ & $\operatorname{tr}$ & $\operatorname{tr}$ & $\mathrm{tr}$ & $\operatorname{tr}$ \\
\hline Rhamnose & - & + & + & + & + & $\operatorname{tr}^{a}$ & $\operatorname{tr}$ & $\operatorname{tr}$ & + & $\operatorname{tr}$ \\
\hline Sucrose & - & + & + & + & - & $\operatorname{tr}^{a}$ & $\operatorname{tr}$ & $\operatorname{tr}$ & + & $\operatorname{tr}$ \\
\hline D-Xylose & + & + & + & + & + & $\operatorname{tr}^{a}$ & + & + & + & + \\
\hline Salicin & + & $-{ }^{a}$ & + & $+{ }^{a}$ & $\operatorname{tr}^{a}$ & $-a$ & $+^{a}$ & $\operatorname{tr}^{a}$ & $\operatorname{tr}^{a}$ & $-{ }^{a}$ \\
\hline \multicolumn{11}{|l|}{ Growth in the presence of ${ }^{k}$ : } \\
\hline Phenol $(0.1 \%)$ & - & $\operatorname{tr}^{a}$ & - & + & $\operatorname{tr}^{a}$ & $-a$ & $\operatorname{tr}^{a}$ & $t^{a}$ & $-a$ & $-a$ \\
\hline Thallium acetate $(100 \mu \mathrm{g} / \mathrm{ml})$ & - & $\operatorname{tr}^{a}$ & - & - & $+^{a}$ & $-{ }^{a}$ & $\operatorname{tr}^{a}$ & $t^{a}$ & $-^{a}$ & $++^{a}$ \\
\hline Crystal violet $(1 \mu \mathrm{g} / \mathrm{ml})$ & + & $-a$ & - & + & $+^{a}$ & $-a$ & $+^{a}$ & $-a$ & $-{ }^{a}$ & $-{ }^{a}$ \\
\hline Streptomycin $(20 \mu \mathrm{g} / \mathrm{ml})$ & - & $-{ }^{a}$ & - & + & - & + or $\operatorname{tr}^{a l, l}$ & $-{ }^{a}$ & $-a$ & $-{ }^{a}$ & $\operatorname{tr}^{a}$ \\
\hline Penicillin $(10 \mu \mathrm{g} / \mathrm{ml})$ & + & $-{ }^{a}$ & - & + & $+^{a}$ & $+^{a}$ & $+^{a}$ & $-{ }^{a}$ & $\operatorname{tr}^{a}$ & $+a$ \\
\hline Minimum $\mathrm{pH}$ for growth & 3.5 & $4.5^{a}$ & 5.0 & 4.0 & $3.5^{a}$ & $4.5^{a}$ & $3.5^{a}$ & $4.2^{a}$ & $4.9^{a}$ & $3.3^{a}$ \\
\hline DL-Diaminopimelic acid & + & + & + & + & + & + & + & + & + & + \\
\hline
\end{tabular}

${ }^{a}$ Data from this study.

${ }^{b}$ Data from reference 3 unless indicated otherwise.

"Data from references 10 and 11 unless indicated otherwise.

"Data from references 9 and 15 unless indicated otherwise.

${ }^{\circ}$ Data from references 18 through 21 unless indicated otherwise.

${ }^{f} \mathrm{~GB}$, gray-brown; BG, brownish gray; BW, brownish white; Y, yellow; CY, creamish yellow; dB, dark brown; G, gray; W-CG, white to carbon gray; BG', bluish gray; $\mathrm{GB}$, gray-black with white specks; W, white; B, brown; G-B, gray to brown; R', red series; Mo, grayish yellow or yellow modified by red; R.G, red or gray; GY, grayish yellow; Y-YB, yellow to yellow-brown; R-BG, red to bluish gray; R, G, typically light grayish reddish brown to light grayish brown; YB, yellowish brown; \pm , not distinctive (grayish yellow to yellowish brown or olive brown); +-, acrial mycelium poorly developed or absent; -, no pigment; R, red.

${ }^{g}$ sp, spiral; f, flexuous; rf, rectiflexuous.

${ }^{h}$ Commonly fewer than 10 spores per chain.

${ }^{i} \mathrm{ND}$, not determined.

'Color on acid media/color on alkaline media.

${ }^{k}-$, negative reaction; + , positive reaction; $\operatorname{tr}$, trace.

'Data from reference 15.

glass capillary column ( $30 \mathrm{~m}$ by $0.25 \mathrm{~mm}$ [inside diameter]) and was programmed to run at $60^{\circ} \mathrm{C}$ for $1 \mathrm{~min}$, after which the temperature was increased at a rate of $4^{\circ} \mathrm{C} / \mathrm{min}$ until it was $250^{\circ} \mathrm{C}$. To differentiate closely related species, a Wilcoxon matched-pair signed-rank test was used to compare the total ion chromatograms (5). Parametric statistics were deemed inappropriate (5) because an assumption of normality in the distribution of chromatographic measurements may not be correct (13) and because, in linear discriminant analysis or multivariate analysis of variance procedures, several hundred samples of data are necessary to adequately describe a multivariate normal population (6). The Wilcoxon signed-rank test takes into account the size of rank order differences within corresponding pairs of peaks.

Cell wall composition. The method of Becker et al. (1a) was slightly modified to determine the presence of the DL or LL form of diaminopimelic acid in the cell wall of strain CR-43 ${ }^{\mathrm{T}}$. Cells of $\mathrm{CR}-43^{\mathrm{T}}$ (test strain) and $S$. hygroscopicus (positive control) were grown for $72 \mathrm{~h}$ in yeast extract-malt extract-glucose medium at $28^{\circ} \mathrm{C}$. Hydrolysates were prepared by autoclaving the biomass in $6 \mathrm{M} \mathrm{HCl}$. 


\section{RESULTS AND DISCUSSION}

Antinematodal strain CR-43 ${ }^{\mathrm{T}}$ was found to be distinctly different from the related Streptomyces type strains used for comparison. Morphological, cultural, and physiological characteristics of the organisms which we studied are summarized in Table 1.

Morphological characteristics. The spore-bearing aerial hyphae of strain CR-43 $3^{\mathrm{T}}$ were simple (nonverticillate), and tightly coiled spiral spore chains were formed on standard ISP agar media (ISP media 2 through 5 ). Each spore chain consisted of 10 to 50 smooth spores. No sclerotium-like bodies, sporangia, or flagellated or conidium-like spores were observed in the aerial or submerged mycelium. Fragmentation of the substrate mycelium was not observed.

Pigmentation. The aerial mycelial mass after 14 days was reddish gray to gray-brown on yeast extract-malt extract agar, oatmeal agar, inorganic salts-starch agar, or glycerol-asparagine agar. A yellow color was produced on ATCC medium 172 (N-Z amine supplemented with soluble starch and glucose). On ISP media 2 and 5 the substrate mycelia were light yellow and yellow to yellowish brown, respectively (golden on ATCC medium 172); no distinctive pigments were produced on ISP medium 3 or 4 agar, although a brown or yellow color was observed. A yellow diffusible pigment was produced on ISP medium 2, ISP medium 5, and ATCC medium 172, and this pigment was not sensitive to $\mathrm{pH}$ changes resulting from additions of $\mathrm{HCl}$ or $\mathrm{NaOH}$. No melanoid pigments were observed on tyrosine agar and peptone-yeast extract-iron agar.

Physiological characteristics. On basal medium (14), CR$43^{\mathrm{T}}$ utilized D-fructose, D-glucose, D-mannitol, D-xylose, salicin, and galactose but not L-arabinose, raffinose, L-rhamnose, and sucrose as sole carbon sources. This pattern of carbon source utilization was different from the patterns of all of the strains used for comparison (Table 1). CR- $43^{\mathrm{T}}$ tolerated $\mathrm{pH}$ values less than 4.0 and grew in the presence of $1 \mu \mathrm{g}$ of crystal violet per $\mathrm{ml}$ or $10 \mathrm{IU}$ of penicillin per ml. Growth was inhibited in media containing $\geq 5 \% \mathrm{NaCl}, 100 \mu \mathrm{g}$ of thallium acetate per $\mathrm{ml}, 0.1 \%$ phenol, or $20 \mu \mathrm{g}$ of streptomycin per ml, while the type strains of other species responded differently. In addition, strain CR $-43^{\mathrm{T}}$ growing in nocardia purple broth produced acid when the medium was supplemented with cellobiose, glucose, glycerol, maltose, galactose, mannitol, or xylose but not when the medium was supplemented with L-arabinose, fructose, lactose, or sucrose. Growth did not occur in nocardia purple broth supplemented with ribitol, galactitol, erythritol, or i-inositol. Strain CR $-43^{\mathrm{T}}$ exhibited antibiotic activity against Rhizoctonia solani and antinematodal activity against $C$. elegans. This antinematodal activity was observed previously in laboratory, greenhouse, and large-scale field trials (4).

Chemical properties. An analysis of whole-cell hydrolysates showed that the DL-diaminopimelic acid isomer (Sigma catalog no. D1377) was present in the cell walls of strain CR-43 ${ }^{\mathrm{T}}$. This provided additional justification for placing CR- $43^{\mathrm{T}}$ in the genus Streptomyces. The fatty acid pattern was characteristic of the genus Streptomyces $(7,8,16)$, and the predominant fatty acids on agar media were a-15:0, 16:0, a-17:0, i-15:0, i-16:0, and i-17:0 (Table 2).

Differentiation from previously described species. Strain CR- $43^{\mathrm{T}}$ was compared with previously described species chosen on the basis of their potential relatedness. A subculture of CR $-43^{\mathrm{T}}$ sent to the ATCC could not be placed in a previously described species (1). After we surveyed the various Streptomyces species described in Bergey's Manual of Determinative Bacteriology, 8th ed. (15), in Bergey's Manual of Systematic Bacteriology (22), and by the ISP (17-21) and after discussions with workers conversant with Streptomyces taxonomy, we found that strain CR $-43^{\mathrm{T}}$ was most similar to the following six species and subspecies: $S$. hygroscopicus, $S$. murinus, $S$. griseoluteus, $S$. hygroscopicus subsp. decoyicus, $S$. rubiginosus, and $S$. griseofuscus. However, CR- $43^{\mathrm{T}}$ differs from these taxa in its total physiological and cultural test reactions, fatty acid profile, and/or gross morphology (Table 1). Culturally, CR $-43^{\mathrm{T}}$ differs from the organism that has the most similar fatty acid profile in agar cultures, the type strain of $S$. murinus, by not producing a soluble pigment when it is grown on oatmeal agar (ISP medium 3) or inorganic salts-starch agar (ISP medium 4). In addition, the $S$. murinus spore mass is red on ISP medium 2, red or gray on ISP medium 3 or 5, and gray on ISP medium 4, while CR $-43^{\mathrm{T}}$ consistently produces a distinct gray-brown color when it sporulates on ISP medium 2, 3, 4, or 5 after 14 days. The substrate mycelium of CR- $43^{\mathrm{T}}$ is brown on oatmeal agar and yellow on inorganic salts-starch agar, while the substrate mycelium of the type strain of $S$. murinus is grayish yellow on oatmeal agar and reddish on inorganic salts-starch agar. CR$43^{\mathrm{T}}$, but not $S$. rubiginosus or $S$. griseofuscus, produces soluble pigments when it is grown on ISP medium 2 or 5 . In addition, $S$. rubiginosus produces spiny spores and utilizes L-rhamnose and sucrose as sole carbon sources; CR $-43^{\mathrm{T}}$ does not utilize L-arabinose, while $S$. griseofuscus does utilize this compound.

To examine the species more critically, nonparametric statistical analyses were used to identify the significantly different fatty acid profiles in pairwise comparisons with CR-43 ${ }^{\mathrm{T}}$. Differences in the total ion chromatograms were analyzed by the Wilcoxon signed-rank test, in which a test criterion and normal deviation for normalized compositions were generated and tested in each comparison by using MSTAT-C software (Michigan State University, East Lansing). All paired comparisons for species grown on solid or liquid medium yielded highly significant differences $(P<0.001)$. The organism that was most similar to CR- $43^{\mathrm{T}}$ culturally and physiologically when the bacteria were grown on solid agar, $S$. murinus NRRL B-2286 ${ }^{\mathrm{T}}$, was easily differentiated from the new strain by comparing the ratios of i-14:0 to $14: 0$, a-15:0 to $16: 0$, and $16: 0$ to a-17:0 in the two organisms. When broth cultures were examined, $S$. hygroscopicus subsp. decoyicus NRRL ISP-5087 $7^{\mathbf{T}}$ had the fatty acid profile that was most similar to the CR $-43^{\mathrm{T}}$ profile. The ratio of i-17:0 (peak 21) to i-15:0 (peak 9), i-16:0 (peak 15), a-17:0 (peak 22), or i-18:0 (peak 29) (which was $<1$ in CR-43 ${ }^{\mathrm{T}}$ but $>1$ in $S$. hygroscopicus subsp. decoyicus) clearly differentiated the two species.

The fatty acid profiles of $S$. hygroscopicus subsp. decoyicus and $S$. murinus were most similar to the CR $-43^{\mathrm{T}}$ profiles (Table 2). Phenotypically, CR $-43^{\mathrm{T}}$ differs from strain NRRL ISP$5087^{\mathrm{T}}$ in that it consistently produces grey-brown spore masses in ISP media 2 through 5 , whereas strain NRRL ISP-5087 ${ }^{\mathrm{T}}$ produces grey spore masses on ISP media 2 and 5 , white to carbon grey spore masses on ISP medium 3 , and grey to brown spore masses on ISP medium 4 after 14 days. Also, CR $-43^{\mathrm{T}}$ can utilize salicin $(1 \mathrm{mg} / \mathrm{ml})$ as a sole carbon source and can grow in the presence of crystal violet $(1 \mu \mathrm{g} / \mathrm{ml})$, whereas strain NRRL ISP-5087 $7^{\mathrm{T}}$ does not grow under these conditions.

On the basis of morphological, cultural, and whole-cell chemical characteristics, CR- $43^{\mathrm{T}}$ is a member of a new Streptomyces species, for which we propose the name Streptomyces costaricanus Esnard, Potter, and Zuckerman. Strain CR-43, the type strain of $S$. costaricanus, has been deposited in the ATCC and U.S. Department of Agriculture Agricultural Research Service Culture Collection as strains ATCC 55274 and NRRL B-16897, respectively.

Description of Streptomyces costaricanus sp. nov. Streptomyces costaricanus (cos.ta.ri.can'us. L. adj. costaricanus, referring 
TABLE 2. Fatty acid compositions of $S$. costaricanus $\mathrm{CR}-43^{\mathrm{T}}$ grown on ISP medium 2 agar and in ISP medium 2 broth

\begin{tabular}{|c|c|c|c|}
\hline \multirow{2}{*}{ Peak no. } & \multirow{2}{*}{ Compound $^{a t}$} & \multicolumn{2}{|c|}{$\%$ on: } \\
\hline & & Agar medium & Broth medium \\
\hline 1 & Benzylacetic acid ${ }^{c}$ & 0.1 & 0.1 \\
\hline 2 & $\mathrm{i}-12: 0$ & $\mathrm{ND}^{d}$ & 0.1 \\
\hline 3 & $12: 0$ & 0.1 & 0.2 \\
\hline 4 & $\mathrm{i}-13: 0$ & 0.1 & 0.2 \\
\hline 5 & $\mathrm{a}-13: 0$ & 0.2 & 0.2 \\
\hline 6 & 13:0 & $<0.1$ & 0.1 \\
\hline 7 & $\mathrm{i}-14: 0$ & 0.6 & 3.8 \\
\hline 8 & 14:0 & 1.0 & 2.4 \\
\hline 9 & $\mathrm{i}-15: 0$ & 8.4 & 6.7 \\
\hline 10 & $a-15: 0$ & 25.2 & 13.6 \\
\hline 11 & br14:0 & $<0.1$ & ND \\
\hline 12 & $15: 0$ & 1.2 & 2.3 \\
\hline 13 & Unknown & 0.1 & 0.1 \\
\hline 14 & $16: 1$ & 0.1 & ND \\
\hline 15 & $\mathrm{i}-16: 0$ & 8.1 & 12.5 \\
\hline 16 & $\mathrm{i}-16: 1$ & 0.3 & 0.2 \\
\hline 17 & Unknown & ND & 0.3 \\
\hline 18 & $16: 0$ & 24.2 & 22.5 \\
\hline 19 & $\mathrm{i}-17: 1$ & 0.3 & 0.2 \\
\hline 20 & $\mathrm{a}-17: 1$ & 0.6 & 0.2 \\
\hline 21 & $\mathrm{i}-17: 0$ & 5.5 & 2.5 \\
\hline 22 & $\mathrm{a}-17: 0$ & 20.3 & 6.7 \\
\hline 23 & br17:0 & ND & 0.3 \\
\hline 24 & cy $17: 0(9)$ & 0.6 & 1.4 \\
\hline 25 & $17: 0$ & 1.0 & ND \\
\hline 26 & Unknown & $<0.1$ & ND \\
\hline 27 & $18: 1$ & $<0.1$ & ND \\
\hline 28 & Unknown (mol wt, 298) & 0.2 & 5.0 \\
\hline 29 & $\mathrm{i}-18: 0$ & 0.2 & 4.9 \\
\hline 30 & Unknown (mol wt, 296) & $<0.1$ & 0.6 \\
\hline 31 & 18:0 & 1.4 & 12.8 \\
\hline 32 & Unknown (mol wt, 290) & 0.1 & 0.1 \\
\hline
\end{tabular}

"Identification of compounds was based on a combination of comparisons with authentic standards, mass spectral interpretation and database searches, and relative gas chromatography retention times. br, branched; cy, cyclo.

"Means from three extractions of growth on ISP medium 2 agar and broth (the coefficient of variation ranged from 0.90 to $2.99 \%$ ).

" The relative retention time of benzylacetic acid was $1.00 \mathrm{~min}$.

${ }^{\text {"ND, not detected. }}$

"The values in parentheses are the molecular weights of methyl esters based on chemical ionization mass spectra.

to Costa Rica, the geographic origin of the organism). Mature spore chains are tightly coiled spirals with 10 to 50 spores per chain. The spores are smooth and gray-brown in mature colonies.

The aerial mycelial mass is grayish brown on yeast extractmalt extract agar, oatmeal agar, inorganic salts-starch agar, and glycerol asparagine agar and yellow on N-Z amine medium containing soluble starch and glucose (ATCC medium 172). The substrate mycelium is light yellow on yeast extract-malt extract agar and glycerol-asparagine agar, golden on ATCC medium 172, brown on oatmeal agar, and yellow on inorganic salts-starch agar. A yellow $\mathrm{pH}$-insensitive diffusible pigment is produced on yeast extract-malt extract agar and glycerol-asparagine agar. The pigment color is orange-yellow on ATCC medium 172. No melanoid pigment is produced on peptoneyeast extract-iron agar or tyrosine agar. The color of the reverse side of the colonies is also not sensitive to $\mathrm{pH}$.

D-Fructose, D-glucose, D-mannitol, D-xylose, salicin, and galactose are utilized for growth, but L-arabinose, raffinose, rhamnose, and sucrose are not utilized. Acid is produced from cellobiose, D-glucose, glycerol, maltose, galactose, D-mannitol, and $\mathrm{D}$-xylose but not from $\mathrm{L}$-arabinose, $\mathrm{D}$-fructose, lactose, and sucrose. No growth occurs in the presence of ribitol, galactitol, erythritol, and i-inositol; $7 \% \mathrm{NaCl}$ is inhibitory. Table 1 shows the tolerance of $S$. costaricanus to other toxic compounds.

Cell walls contain LL-diaminopimelic acid. The most abundant hydrolyzable fatty acids are a-15:0, 16:0, a-17:0, i-15:0, $\mathrm{i}-16: 0$, and $\mathrm{i}-17: 0$ in cells grown on ISP medium 2 agar. The concentration of octadecanoic acid is ninefold higher in ISP medium 2 broth (Table 2). Isolated from a tropical soil. Exhibits antinematodal activity against $C$. elegans and antibiotic activity against $R$. solani and Pythium aphanidermatum. The type strain is strain CR-43 (= ATCC $55274=$ NRRL B-16897).

\section{ACKNOWLEDGMENTS}

We thank D. Labeda (U.S. Department of Agriculture Agricultural Research Service) for expert advice. D. Labeda and R. Loria (Cornell University) kindly supplied strains for comparison. We acknowledge the advice of the late Irving Fagerson and Tom Carpenter concerning the chemical analyses and the technical assistance of B. Kelly, G. Coles, R. Wick, and B. Dicklow in some stages of this investigation.

This work was supported by a grant to B. M. Zuckerman from the Corporation for the Technological Development of Tropical Resources, Commonwealth of Puerto Rico.

\section{REFERENCES}

1. American Type Culture Collection. 1990. Report SC2285. American Type Culture Collection, Rockville, Md.

1a.Becker, B., M. P. Lechevalier, R. E. Gordan, and H. A. Lechevalier. 1964. Rapid differentiation between Nocardia and Streptomyces by paper chromatography of whole-cell hydrolysates. Appl. Microbiol. 12:421-423.

2. Brenner, S. 1974. The genetics of Caenorhaditis elegans. Genetics 77:71-94.

3. Burg, R. W., B. M. Miller, E. E. Baker, J. Birnbaum, S. A. Currie, R. Hartman, Y.-L. Kong, R. L. Monaghan, G. Olson, I. Putter, J. B. Tunac, H. Wallick, E. O. Stapley, R. Oiwa, and S. Omura. 1979. Avermectins, new family of potent anthelmintic agents: producing organism and fermentation. J. Antibiot. 15:361-367.

4. Dicklow, M. B., N. Acosta, and B. M. Zuckerman. 1993. A novel Streptomyces species for controlling plant-parasitic nematodes. J. Chem. Ecol. 19:159-173.

5. Esnard, J., T. L. Potter, and B. M. Zuckerman. 1994. Differentiation of six strains of Bacillus thuningiensis by hydrolyzable fatty acid composition. J. Agric. Food Chem. 5:1251-1255.

6. Han, J. H., A. J. I. Ward, and B. K. Lavine. 1990. The problem of adequate sample size in pattern recognition studies: the multivariate normal case. $J$. Chemometrics 4:91-96.

7. Kataoka, T., and S. Nojima. 1967. The phospholipid compositions of some actinomycetes. Biochim. Biophys. Acta 144:681-683.

8. Kroppenstedt, R. M. 1985 . Fatty acid and menaquinone analysis of actinomycetes and related organisms, p. 173-199. In M. Goodfellow and D. E. Minnikin (ed.), Chemical methods in bacterial systematics. Academic Press, London.

9. Labeda, D. P., and A. J. Lyons. 1991. The Streptomyces violaceusniger cluster is heterogeneous in DNA relatedness among strains: emendation of the descriptions of $S$. violaceusniger and Streptomyces hygroscopicus. Int. J. Syst. Bacteriol. 41:398-401.

10. Lambert, D. H., and R. Loria. 1989. Streptomyces acidiscabies sp. nov. Int. J. Syst. Bacteriol. 39:393-396.

11. Lambert, D. H., and R. Loria. 1989. Streptomyces scabies sp. nov., nom. rev. Int. J. Syst. Bacteriol. 39:387-392.

12. Lumsden, R. D., R. Garcia-E., J. A. Lewis, and T. A. Fries. 1987. Suppression of damping-off caused by Pythium spp. in soil from the indigenous chinampa agricultural system. Soil Biol. Biochem. 19:501-508.

13. Massart, D. L., and L. Kaufman. 1983. The interpretation of analytical chemical data by the use of cluster analysis. John Wiley \& Sons, New York.

14. Pridham, T. G., and D. Gottlieb. 1948. The utilization of carbon compounds by some Actinomycetales as an aid for species determination. J. Bacteriol. 56: $107-114$.

15. Pridham, T. G., and H. D. Tresner. 1974. Genus I. Streptomyces Waksman and Henrici 1943, 339, p. 748-829. In R. E. Buchanan and N. E. Gibbons (ed.), Bergey's manual of determinative bacteriology, 8 th ed. The Williams \& Wilkins Co., Baltimore.

16. Saddler, G. S., A. G. O'Donnel, M. Goodfellow, and D. E. Minnikin. 1987 SIMCA pattern recognition on the analysis of streptomycete fatty acids. J. Gen. Microbiol. 133:1137-1147. 
17. Shirling, E. B., and D. Gottlieb. 1966, Methods for characterization of Streptomyces species. Int. J. Syst. Bacteriol. 16:313-340.

18. Shirling, E. B., and D. Gottlieb. 1968. Cooperative description of type cultures of Streptomyces. II. Species descriptions from first study. Int. J. Syst. Bacteriol. 18:69-189.

19. Shirling, E. B., and D. Gottlieb. 1968. Cooperative description of type cultures of Streptomyces. III. Additional species description from first and second studies. Int. J. Syst. Bacteriol. 18:279-392.

20. Shirling, E. B., and D. Gottlieb. 1968. Cooperative description of type cultures of Streptomyces. IV. Species description from second, third, and fourth studies. Int. J. Syst. Bacteriol. 19:391-512.
21. Shirling, E. B., and D. Gottlieb. 1972. Cooperative description of type strains of Streptomyces. V. Additional descriptions. Int. J. Syst. Bacteriol. 22:265394.

22. Williams, S. T., M. Goodfellow, and G. Alderson. 1989. Genus Streptomyces Waksman and Henrici, 1943, 339 AL, p. 2452-2492. In S. T. Williams, M. E. Sharpe, and J. G. Holt (ed.), Bergey's manual of systematic bacteriology, vol. 4. The Williams \& Wilkins Co., Baltimore.

23. Zuckerman, B. M., M. B. Dicklow, G. C. Coles, R. Garcia-E., and N. Marban-Mendoza. 1989. Suppression of plant-parasitic nematodes in the chinampa agricultural soils. J. Chem. Ecol. 15:1947-1955. 